\title{
Experimental investigation on the repair of rammed earth by means of injection of mud grouts
}

\author{
R.A. Silva, D.V. Oliveira \& P.B. Lourenço \\ ISISE, University of Minho, Guimarães, Portugal \\ L. Schueremans \\ Department of Civil Engineering, KULeuven, Heverlee, Belgium
}

T. Miranda

C-TAC, University of Minho, Guimarães, Portugal

\begin{abstract}
This paper assesses the adhesion capacity of unmodified mud grouts used to repair structural cracks on medium and large scale rammed earth specimens. Beam and wallet-specimens were manufactured using a soil from Alentejo (Portugal), whose particle size distribution had to be first corrected due to its high clay content. An "artificial" (composed by kaolin and limestone powder) and a "natural" (composed by sieved soil and limestone powder) mud grout were used to repair the specimens, which were previously tested under three-point bending and diagonal-compression and then retested. The grout injection shown to provide satisfactory results regarding the adhesion capacity, but only if it is performed with the "natural" mud grout.
\end{abstract}

\section{INTRODUCTION}

The successful conservation of the earth built heritage requires employing adequate intervention techniques. This means that the intervention techniques, and thus the intervention materials, must be compatible with the original ones. Otherwise, the intervention is more prone to promote damage and durability problems, rather than solving the initial problems of the construction (Keefe 2005).

The presence of cracks is a common form of structural damage found in rammed earth constructions and is a consequence of several agents as: settlements of the foundations, concentrated loads, horizontal thrusts and earthquakes (Warren 1999). This type of damage on rammed earth walls debilitates their acknowledged monolithic structural behaviour in terms of a decrease in strength and in stiffness. Furthermore, the presence of cracks constitutes a path for further decay, namely through rainwater infiltration.

Several techniques can be used to repair cracks, but their efficiency greatly varies from case to case. The most basic technique consists in simply filling the crack with a compatible earth mortar. However, and despite the barrier against rainwater that the filling mortar constitutes, it is inefficient regarding the re-establishment of the mechanical continuity disrupted by the crack. This is mainly due to the inability of the mortar to penetrate in the full extension of the crack. The drying shrinkage of the earth mortar is another factor contributing for the inefficiency of this technique. Regarding the first limitation, the injection of grouts is a technique with possible better results, but both short-term and long-term success requires the employment of compatible grouts.

Currently, there are several published works on grouts for the consolidation of historical masonry (Vintzileou \& Tassios 1995, Toumbakari 2002 and Vintzileou \& Miltiadou-Fezans 2008), where the most recent ones highlight the importance of the use of binary and ternary grouts, which have compositions similar to historical mortars (by incorporating lime, pozzolanas and low percentages of cement). On the other hand, there are only few publications reporting the injection of earth constructions (Roselund 1990, Jäger \& Fuchs 2008, Vargas et al. 2008, On Yee 2009, Silva et al. 2012). These publications suggest different compositions of grouts, but all agree that an adequate grout should incorporate earth (mud grouts). As it is known, earthen materials shrink upon drying, compromising their adhesion capacity, thus most of the mud grouts presented in these publications also incorporate binders such as lime, cement and gypsum (modified mud grouts). However, Vargas et al. (2008) has shown that unmodified mud grouts 
(not incorporating additional binders) are capable of providing better adhesion in adobe walls than the modified ones. This means that the clay fraction of unmodified mud grouts may constitute an adequate binder itself and that its drying shrinkage may not be so limiting in terms of adhesion capacity.

Most recently, Silva et al. (2012) has analysed the influence of the composition of unmodified mud grouts on their fresh-state rheology and hardenedstate strength and adhesion capacity. However, the characterization of this last property was tested resorting to small-scale rammed earth specimens, which may not be representative of a full-scale rammed earth wall. Following the research work in Silva et al. (2012), this paper tries to answer to the referred limitation by presenting the results of three-point bending and diagonal-compression tests. The rammed earth specimens were manufactured with a soil collected in Alentejo (Portugal), where this type of earthen construction is common. Firstly, the suitability of the soil for rammed earth construction was assessed and resulted in a proposed PSD (particles size distribution) correction, used to manufacture the specimens. After a first test, injecting two compositions of unmodified mud grouts repaired the specimens. The two assessed grouts include an "artificial" grout composed by kaolin and limestone powder, and a "natural" grout composed by sieved soil and limestone powder.

\section{PREPARATION OF THE SPECIMENS}

\subsection{Soil assessment for rammed earth construction}

The soil used to manufacture the specimens was collected from Amoreiras-Gare (Odemira, Alentejo) and was characterized by means of expeditious (sedimentation test, ribbon test, drop test and dry strength test) and laboratory tests (PSD analysis, consistency limits and standard Proctor) to assess its suitability for unstabilised rammed earth construction.

In general, the expeditious tests revealed that the clay content of the soil was excessively high, as confirmed by its PSD curve (Fig. 1), which shows clay content of about $28 \%$. Furthermore, the PSD curve of the soil does not respect the recommended PSD envelope for rammed earth, given by Houben \& Guillaud (2008).

The excessive clay content of the soil may result in a rammed earth material with excessive drying shrinkage, whereby it is possible to conclude that this soil is not suitable for rammed earth construction in its natural state. Furthermore, Table 1

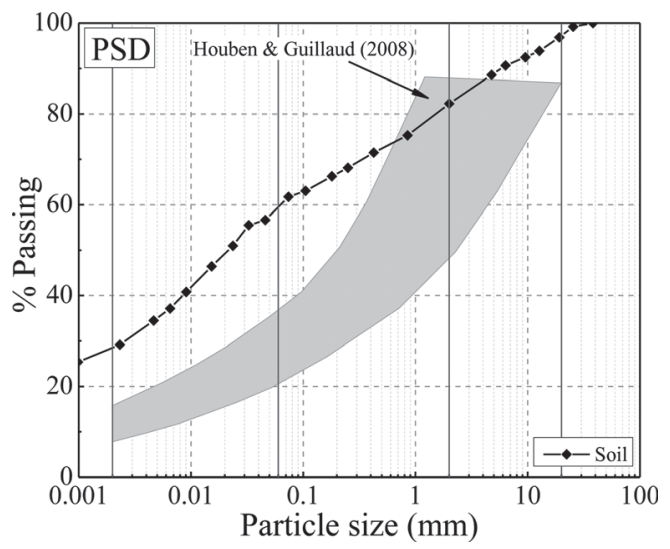

Figure 1. PSD of the soil and comparison with the envelope for rammed earth construction recommended by Houben \& Guillaud (2008). (Credits: Authors).

Table 1. Consistency limits and compaction properties of the soil.

\begin{tabular}{llllll}
\hline $\begin{array}{l}\mathrm{LL} \\
(\%)\end{array}$ & $\begin{array}{l}\mathrm{PL} \\
(\%)\end{array}$ & $\begin{array}{l}\text { PI } \\
(\%)\end{array}$ & $\begin{array}{l}\rho_{\text {dmax }} \\
\left(\mathrm{g} / \mathrm{cm}^{3}\right)\end{array}$ & $\begin{array}{l}\text { OWC } \\
(\%)\end{array}$ & $\begin{array}{l}G_{s} \\
(-)\end{array}$ \\
\hline 30 & 18 & 12 & 1.83 & 13.4 & 2.68 \\
\hline
\end{tabular}

presents the consistency limits and compaction properties of the soil, from where it is highlighted its relatively low maximum dry density $\left(\rho_{\text {dmax }}\right)$ for rammed earth construction. This is a result of a poorly distributed PSD and may mean that the strength of unstabilised rammed earth manufactured with this soil would possibly be low. Thus, it was decided to proceed with the PSD correction of the soil to manufacture the rammed earth specimens, knowing beforehand that this is a practice used locally in Odemira.

\subsection{PSD correction of the soil}

The PSD correction was carried out by means of the addition of river sand and gravel obtained from crushed granite. The PSD curves of these two aggregates are given in Figure 2, as well the PSD of the corrected soil. The correction consisted in adjusting the curve of the mixture of soil, sand and gravel to the full curve of Equation (1), recommended by Houben \& Guillaud (2008), in order to optimize the density of the material and, thus, its strength performance.

$P=\left(\frac{d}{D}\right)^{0}$ 


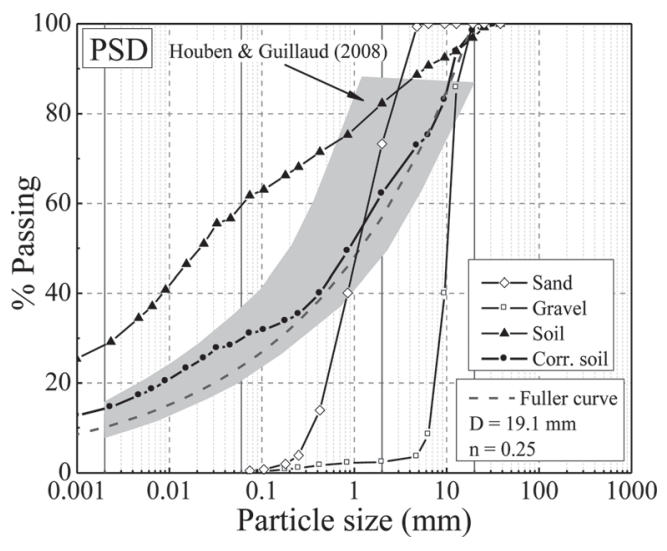

Figure 2. PSD curves of the corrective aggregates and of the corrected soil. (Credits: Authors).

Table 2. Consistency limits and compaction properties of the corrected soil.

\begin{tabular}{llllll}
\hline $\begin{array}{l}\mathrm{LL} \\
(\%)\end{array}$ & $\begin{array}{l}\mathrm{PL} \\
(\%)\end{array}$ & $\begin{array}{l}\text { PI } \\
(\%)\end{array}$ & $\begin{array}{l}\rho_{\text {dmax }} \\
\left(\mathrm{g} / \mathrm{cm}^{3}\right)\end{array}$ & $\begin{array}{l}\text { OWC } \\
(\%)\end{array}$ & $\begin{array}{l}G_{s} \\
(-)\end{array}$ \\
\hline 23 & 16 & 7 & 2.10 & 10.1 & 2.68 \\
\hline
\end{tabular}

where $P$ is the percentage finer than the size being considered, $d$ is the size being considered and $D$ is the maximum size of the particles.

The resulting corrected soil was composed by $50 \%$ of soil, $28 \%$ of river sand and $22 \%$ of gravel (in weight). The properties of the corrected soil are given in Table 2.

\subsection{Performance in compression}

The performance in compression of the rammed earth manufactured with the corrected soil was assessed by compression tests on six cylindrical specimens compacted with maximum dry density and OWC. The specimens were compacted with three layers in a metallic mould with dimensions of $100 \mathrm{~mm}$ diameter and $200 \mathrm{~mm}$ height. An electric rammer was used for this process and the specimens were demolded immediately after their compaction.

The tests were carried out after the specimens achieved their equilibrium water content at $20^{\circ} \mathrm{C}$ temperature and $57.5 \%$ relative humidity (drying period between 27 and 35 days). The vertical deformations at the middle third of each specimen were measured by means of three LVDTs radially disposed. The load was applied in displacement control at a rate of $3 \mu \mathrm{m} / \mathrm{s}$. In the day before testing, the specimens had their top and bottom capped by a layer of gypsum.

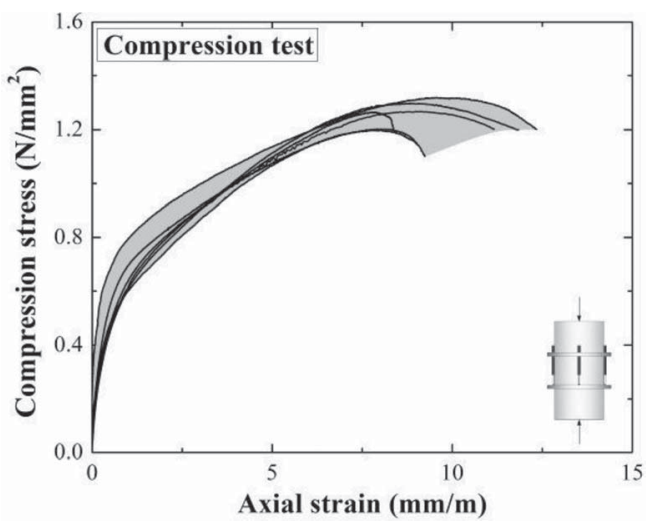

Figure 3. Compression stress-strain curves of the rammed earth cylindrical specimens manufactured with the corrected soil. (Credits: Authors).

Table 3. Results of the rammed earth cylindrical specimens tested under compression.

\begin{tabular}{llcl}
\hline Specimen & $f_{c}\left(\mathrm{~N} / \mathrm{mm}^{2}\right)$ & $E_{0}\left(\mathrm{~N} / \mathrm{mm}^{2}\right)$ & $W_{e q}(\%)$ \\
\hline CURES6_1 & 1.27 & 865 & 1.12 \\
CURES6_2 & 1.20 & 1408 & 1.05 \\
CURES6_3 & 1.20 & 1112 & 1.04 \\
CURES6_4 & 1.32 & $3160^{\dagger}$ & 0.98 \\
CURES6_5 & 1.27 & 960 & 1.04 \\
CURES6_6 & 1.30 & 827 & 1.03 \\
Average & 1.26 & 1034 & 1.04 \\
COV $(\%)$ & 4.0 & 22.8 & 4.4 \\
\hline
\end{tabular}

Outlier, thus not considered for statistical analysis.

The stress-strain curves of the specimens and the respective envelope are presented in Figure 3. Table 3 summarizes the results in terms compressive strength $\left(f_{c}\right)$, Young modulus $\left(E_{0}\right)$ and equilibrium water content $\left(W_{e q}\right)$.

The average compressive strength was of about $1.26 \mathrm{~N} / \mathrm{mm}^{2}$ and was obtained for average equilibrium water content of about $1.04 \%$. Moreover, the results obtained for the compressive strength deem with the minimum requirements defined by the NZS 4298 (NZS 1998a), even that barely; the least value of the set of six specimens $\left(1.20 \mathrm{~N} / \mathrm{mm}^{2}\right)$ must be greater than $1.14 \mathrm{~N} / \mathrm{mm}^{2}$. The Young modulus $\left(E_{0}\right)$ was computed between $5 \%$ and $30 \%$ of the compressive strength of the respective specimen by linear fitting. It should be noted that the Young modulus of specimen CURES6_4 seems to deviate remarkably from that of the others specimens, and thus it was not considered for statistical analysis of the results regarding the Young modulus. Thus, the average Young modulus is of about $1034 \mathrm{~N} / \mathrm{mm}^{2}$. In average, the Young modulus is about 820 times 


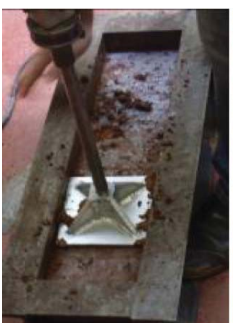

(a)

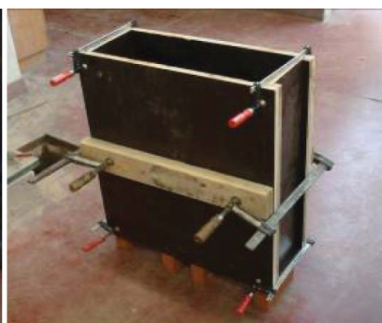

(b)
Figure 4. Preparation of the (a) three-point bending and (b) diagonal compression specimens. (Credits: Authors).

higher than the compressive strength, which means that the standard NZS 4297 (NZS 1998b) underestimates this parameter (300 times higher than $f$ ). However it should be noted that, the Young modulus is a parameter of high variability and depends greatly on the properties of the soil.

\subsection{Manufacture of the specimens}

As stated, the adhesion capacity of two mud grouts was assessed by means of three-point bending and diagonal-compression tests on specimens manufactured with the corrected soil. The three-point bending specimens consisted of beams with dimensions $150 \times 150 \times 600 \mathrm{~mm}^{3}$, which were compacted in three layers of similar thickness, using a metallic mould (Figure 4a). The diagonal-compression specimens consisted of wallets with dimensions $550 \times 550 \times 200 \mathrm{~mm}^{3}$, which were compacted in 9 layers of similar thickness, using a high-density plywood formwork (Figure 4b).

The water content of the corrected soil for initiating the compaction was controlled by means of the drop test and all the specimens were demolded immediately after compaction. A total of 12 beamspecimens and 5 wallet-specimens were prepared.

\section{TESTING AND REPAIR PROCEDURES}

\subsection{Testing procedures}

The beam-specimens were first tested under threepoint bending after drying for 6 weeks under a room temperature of about $22 \pm 2^{\circ} \mathrm{C}$. The load was applied at middle span and the distance between supports was of about $500 \mathrm{~mm}$ (Fig. 5a). The application of the load was carried out under monotonic displacement control at a rate of $1 \mu \mathrm{m} / \mathrm{s}$. The testing procedure of the specimens after injection was similar, but the tests were carried out 3 weeks after the repair. The drying was processed under a room

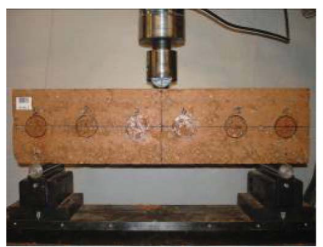

(a)

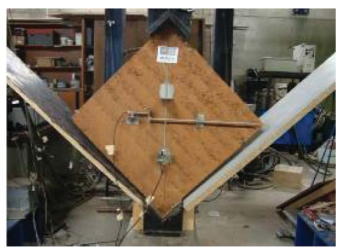

(b)
Figure 5. Tests carried out on the rammed earth specimens: (a) three-point bending and (b) diagonal-compression. (Credits: Authors).

temperature similar to that of the specimens before testing. It should be noted that only the maximum force was recorded from these tests.

The wallet-specimens were first tested under diagonal-compression after drying for about 12 weeks under a room temperature of about $22 \pm 2^{\circ} \mathrm{C}$. The test was carried out according to ASTM E519 (ASTM 2002). The supports were $100 \mathrm{~mm}$ width and the load was applied under monotonic displacement control at a rate of $2 \mu \mathrm{m} / \mathrm{s}$. The vertical and horizontal displacements were measured in both faces of the wallet, resorting to LVDTs attached to the middle third of each diagonal (Fig. 5b). The same testing procedure was followed after repairing the wallets, which were tested 5 weeks later.

\subsection{Mud Grouts}

The compositions of the two grouts used within the experimental program are given in Table 4 . The grout A is an "artificial" mud grout, constituted by kaolin powder (Mibal-A) and limestone powder (200-OU). Grouts B is a "natural" mud grout constituted by sieved soil (the same soil used in the manufacture of the specimens) with maximum particle size of about $0.18 \mathrm{~mm}(\mathrm{~S} \# 80)$ and limestone powder (Micro 200-OU) (see Figure 6 for PSD). Moreover, all mud grouts included the addition of sodium hexametaphosphate (HMP) to improve fluidity while keeping a low $W / S$. The Marsh cone (EN 445 - CEN 2007) flow time (1 $\mathrm{dm}^{3}$ of grout), flexural strength and compressive strength (EN 1015-11 - CEN 1999) of each grout are given in Table 5.

\subsection{Repair of the beam-specimens}

The failure of the beam-specimens resulted in two parts divided by a middle span crack. These parts were then bonded together using the mud grouts $\mathrm{A}$ and $\mathrm{B}$, which were injected in the crack. Before injection, the crack surfaces were brushed to remove loose materials and were sprayed with water 
Table 4. Composition of the mud grouts.

\begin{tabular}{llllll}
\hline $\begin{array}{l}\text { Mud } \\
\text { Grout }\end{array}$ & $\begin{array}{l}\text { Mibal-A } \\
(\text { wt.\%) }\end{array}$ & $\begin{array}{l}\text { S\#80 } \\
(\text { wt.\%) }\end{array}$ & $\begin{array}{l}\text { 200-OU } \\
(\text { wt. \%) }\end{array}$ & $\begin{array}{l}\text { HMP } \\
(\text { wt.\%) }\end{array}$ & W/S \\
\hline A & 20 & - & 80 & 0.40 & 0.30 \\
B & - & 40 & 60 & 0.46 & 0.30 \\
\hline
\end{tabular}

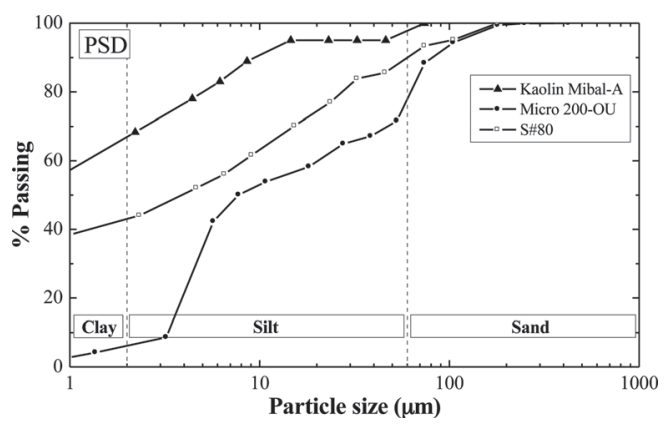

Figure 6. PSD curves of the materials composing the mud grouts.( Credits: Authors).

Table 5. Properties of the mud grouts.

\begin{tabular}{llll}
\hline $\begin{array}{l}\text { Mud } \\
\text { Grout }\end{array}$ & $\begin{array}{l}\text { Flow } \\
\text { time }(\mathrm{s})\end{array}$ & $\begin{array}{l}f_{b} \\
\left(\mathrm{~N} / \mathrm{mm}^{2}\right)\end{array}$ & $\begin{array}{l}f_{c} \\
\left(\mathrm{~N} / \mathrm{mm}^{2}\right)\end{array}$ \\
\hline A & 85.9 & 0.62 & 1.48 \\
$\mathrm{~B}$ & 36.5 & 0.92 & 2.44 \\
\hline
\end{tabular}

to mitigate the water sorption during the injection (Figure 7a). The base of the specimens was sealed using a plywood board and silicone sealant, while the sides were sealed with silicone and Plexiglas plates pressed against the specimen by means of two screw clamps. This apparatus allowed visualising the rising of the mud grout within the crack during the injection. The specimens' parts were positioned on the board such that the gap width $\left(d_{c r}\right)$ would be of about $2 \mathrm{~mm}$ or $8 \mathrm{~mm}$, totalizing 6 specimens for each case. The injection was performed using a $100 \mathrm{ml}$ syringe coupled to a $4 \mathrm{~mm}$ diameter tube installed at the bottom of one of the Plexiglas plates. For each set of six specimens with the same $d_{c r}$, three specimens were injected with grout $\mathrm{A}$ and other three with grout $\mathrm{B}$.

\subsection{Repair of the wallet-specimens}

The failure of the wallets resulted in the division of the specimens in some parts, which were removed from the testing apparatus and remounted together. The cracks were sealed using an earth

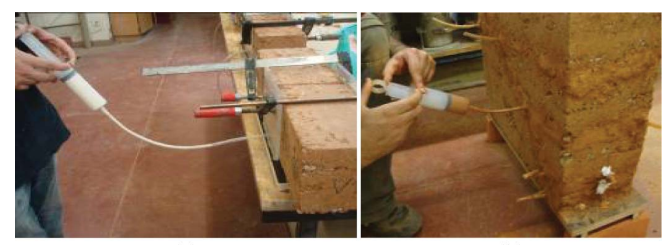

(a)

(b)

Figure 7. Injection of the (a) beam-specimens and (b) wallet-specimens. (Credits: Authors).

mortar prepared with soil sieved through ASTM sieve \#4. Plastic tubes with $6 \mathrm{~mm}$ diameter were installed in one of the sides of the specimens such that they penetrated about $4 \mathrm{~cm}$ in the wallets and that their spacing was inferior to $10 \mathrm{~cm}$. A $100 \mathrm{ml}$ syringe with water was injected in all tubes 1 hour before injecting the grouts in order to mitigate the water sorption by the wallets. Only the grout B was used to inject the five specimens, and their injection started from the bottom tubes up to the top ones, using the same $100 \mathrm{ml}$ syringe (Fig. 7b).

\section{RESULTS AND DISCUSSION}

Regarding the injectability of the mud grouts, it should be mentioned that none of the grouts registered difficulties in penetrating through the two types of cracks considered for the beam specimens. The same occurred in the injection of the wallets. This means that the fluidity of the grouts and their water retention capacity are adequate to allow their injection without experiencing excessive water sorption by the rammed earth specimens. However, the high water sorption capacity of the rammed earth specimens was thoroughly observed, since the grouts presented a hardened state in about 10 minutes after their injection. Thus the working time to inject these grouts into an injection tube is expected to be less than 10 minutes, especially in hot ambient conditions.

Table 6 summarizes the results of the three-point bending tests in terms of initial flexural strength $\left(f_{b i}\right)$, flexural strength after grout injection $\left(f_{b g}\right)$ and the recovery rate $f_{b s} / f_{b i}$. Grout A shows poor recovery rate for both tested gap widths, where for $d_{c r}=2 \mathrm{~mm}$ the average recovery rate was of about $26 \%$, while that for $d_{c r}=8 \mathrm{~mm}$ was of about $17 \%$.

Grout B, on the other hand, shows very satisfactory adhesion capacity by presenting an average recovery rate of about $55 \%$ for $d_{c r}=2 \mathrm{~mm}$ and of about $74 \%$ for $d_{c r}=8 \mathrm{~mm}$. Even though grout $\mathrm{B}$ is stronger than grout $\mathrm{A}$, this fact does not justifies the unsatisfactory results obtained for grout $\mathrm{A}$. Probably this difference can be explained by differences in the clay fraction of both grouts, where 
Table 6. Results of the three-point bending tests.

\begin{tabular}{llllll}
\hline Specimen & $\begin{array}{l}d_{c r} \\
(\mathrm{~mm})\end{array}$ & Grout & $\begin{array}{l}f_{b i} \\
\left(\mathrm{~N} / \mathrm{mm}^{2}\right)\end{array}$ & $\begin{array}{l}f_{b g} \\
\left(\mathrm{~N} / \mathrm{mm}^{2}\right)\end{array}$ & $\begin{array}{l}f_{b g} / f_{b i} \\
(\%)\end{array}$ \\
\hline BURE_1 & 2 & A & 0.26 & 0.07 & 27 \\
BURE_2 & 2 & A & 0.21 & 0.06 & 31 \\
BURE_3 & 2 & A & 0.18 & 0.04 & 20 \\
Average & - & - & 0.22 & 0.06 & 26 \\
BURE_4 & 8 & A & 0.23 & 0.03 & 13 \\
BURE_5 & 8 & A & 0.22 & 0.05 & 21 \\
BURE_6 & 8 & A & 0.18 & 0.03 & 18 \\
Average & - & - & 0.21 & 0.04 & 17 \\
BURE_7 & 2 & B & 0.19 & 0.13 & 69 \\
BURE_8 & 2 & B & 0.17 & 0.09 & 55 \\
BURE_9 & 2 & B & 0.24 & 0.09 & 39 \\
Average & & & 0.20 & 0.11 & 55 \\
BURE_10 & 8 & B & 0.26 & 0.16 & 59 \\
BURE_11 & 8 & B & 0.23 & 0.19 & 83 \\
BURE_12 & 8 & B & 0.30 & 0.24 & 79 \\
Average & - & - & 0.26 & 0.20 & 74 \\
\hline
\end{tabular}

Table 7. Results of the diagonal-compression tests.

\begin{tabular}{llllll}
\hline Specimen & $\begin{array}{l}f_{s i} \\
\left(\mathrm{~N} / \mathrm{mm}^{2}\right)\end{array}$ & $\begin{array}{l}f_{s g} \\
\left(\mathrm{~N} / \mathrm{mm}^{2}\right)\end{array}$ & $\begin{array}{l}f_{s g} / f_{s i} \\
(\%)\end{array}$ & $\begin{array}{l}G_{0 i} \\
\left(\mathrm{~N} / \mathrm{mm}^{2}\right)\end{array}$ & $\begin{array}{l}G_{0 g} \\
\left(\mathrm{~N} / \mathrm{mm}^{2}\right)\end{array}$ \\
\hline WURE_1 & 0.17 & 0.07 & 39 & 659 & 67 \\
WURE_2 & 0.16 & 0.15 & 93 & 705 & 53 \\
WURE_3 & 0.13 & 0.06 & 43 & 413 & 47 \\
WURE_4 & 0.14 & 0.09 & 68 & 341 & 54 \\
WURE_5 & 0.14 & 0.12 & 89 & 732 & 142 \\
Average & 0.15 & 0.10 & 66 & 570 & 73 \\
COV $(\%)$ & 10 & 40 & 38 & 32 & 54 \\
\hline
\end{tabular}

that of grout B is similar to that of the beam-specimens, since it is composed by the respective soil. Therefore, this result seems to encourage using the same soil used in the construction to compose a mud grout in a repair intervention. The unsatisfactory result for grout $\mathrm{A}$ justifies why this grout was not considered for repairing the wallet-specimens.

Table 7 summarizes the results of the diagonalcompression tests carried out on the wallets, in terms of shear strength $\left(f_{s i}\right)$ and shear modulus $\left(G_{0 i}\right)$ before injection, shear strength $\left(f_{s g}\right)$ and shear modulus $\left(G_{0 g}\right)$ after injection, and shear strength recovery rate $\left(f_{s g} / f_{s i}\right)$. Again, grout B showed to provide a very satisfactory performance regarding the adhesion capacity; in average the recovery rate was of about $66 \%$ for the shear strength. This result highlights again the importance of using the soil employed in the rammed earth construction in the composition of the grout.

Table 7. Results of the diagonal-compression tests.

As a result of the repair, the shear modulus decreased about one order of magnitude relative to

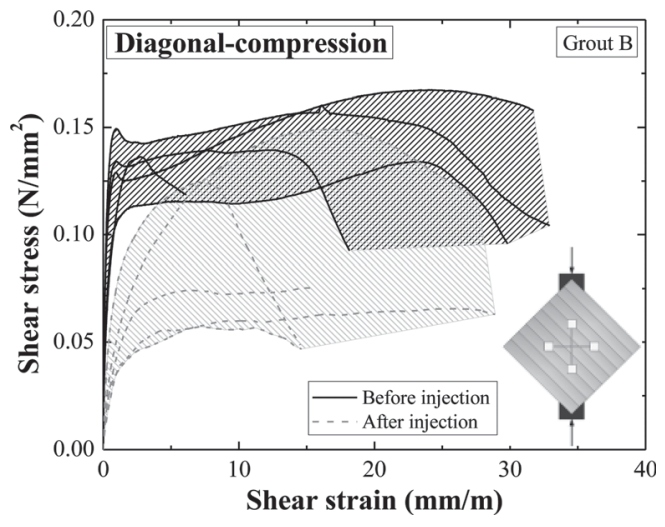

Figure 8. Shear stress-shear strain curves of the wallets before and after injection. (Credits: Authors).

the initial state of the specimens. The injection of mud grout $\mathrm{B}$ was unable to recover the initial shear stiffness of the wallets, but it allowed similar level of deformations (Fig. 8). This is a consequence of the absence of coarse aggregates in the failure surface of the wallets after injection, which is almost coincident with that before injection. These aggregates promote stiffness due to their interlocking effect, but they were lost in the reassembling of the specimens and were not reintroduced with the injection.

\section{CONCLUSIONS}

This paper deals with the repair of cracks on damaged rammed earth walls, by focusing the adhesion capacity of two unmodified mud grouts on medium and large scale specimens. An "artificial" mud grout (grout A) presented unsatisfactory results regarding the recovery of the flexural strength of rammed earth beam-specimens. On the other hand, a "natural" mud grout (grout B) showed satisfactory results both in recovering the flexural strength and shear strength of the beam and wallet-specimens, respectively. Given that, the grout injection seems to be a feasible and reliable technique to recover the structural integrity of cracked rammed earth walls. Furthermore, it is recommended to employ the same soil used in the construction to compose the mud grout, both for compatibility and adhesion capacity reasons.

\section{ACKNOWLEDGEMENTS}

The authors wish to express their gratitude to the Portuguese Science and Technology Foundation for 
the scholarship granted (SFRH/BD/39145/2007), to Monumenta Lda for providing the soil and to Júlio Machado for its precious help in the experimental work.

\section{REFERENCES}

ASTM, 2002. ASTM E519-02: Standard Test Method for Diagonal Tension (Shear) in Masonry Assemblages. American Society for Testing and Materials, West Conshohocken, PA.

CEN, 1999. EN 1015-11: Methods of test for mortar for masonry - Part 11: Determination of flexural and compressive strength of hardened mortar. European Committee for Standardization.

CEN, 2007. EN 445: Grout for Prestressing Tendons-Test Methods European Committee for Standardization.

Houben, H. \& Guillaud, H. ed., 1994. Earth Construction: A Comprehensive Guide, London: Intermediate Technology Development Group.

Jäger, W. \& Fuchs, C. 2008. Reconstruction of the Sistani House at Bam Citadel after the collapse due to the earthquake 2003. In VI International Conference on Structural Analysis of Historic Constructions: Bath, pp.1181-1187.

Keefe, L. ed. 2005. Earth Building: Methods and materials, repair and conservation. London: Taylor \& Francis.

NZS 1998a. New Zealand Standard 4298: 1998, Materials and workmanship for earth buildings. Wellington: Standards New Zealand.
NZS 1998b. New Zealand Standard 4297:1998, Engineering design of earth buildings. Wellington: Standards New Zealand.

On Yee, L. 2009. Study of earth-grout mixtures for rehabilitation. Guimarães: University of Minho.

Roselund, N., 1990. Repair of cracked walls by injection of modified mud. In 6th International Conference on the Conservation of Earthen Architecture: Adobe 90 Preprints: Las Cruces, pp.336-341.

Silva, R.A. Schueremans, L. Oliveira, D.V. Dekoning, K. \& Gyssels T. 2012. On the development of unmodified mud grouts for repairing earth constructions: rheology, strength and adhesion. Materials and Structures 45(10): 1497-1512.

Toumbakari, E. 2002. Lime-Pozzolan-Cement Grouts and their Structural Effects on Composite Masonry Walls. Leuven: Catholic University of Leuven.

Vargas, J., Blondet, M., Cancino, C., Ginocchio, F., Iwaki, C. \& Morales, K., 2008. Experimental results on the use of mud-based grouts to repair seismic cracks on adobe walls. In VI International Conference on Structural Analysis of Historic Constructions: Bath, pp.1095-1099.

Vintzileou, E. \& Miltiadou-Fezans, A., 2008. Mechanical properties of three-leaf stone masonry grouted with ternary or hydraulic lime-based grouts. Engineering Structures 30(8): 2265-2276.

Vintzileou, E. \& Tassios, T.P. 1995. Three-leaf stone masonry strengthened by injecting cement grouts. Journal of Structural Engineering 121(5): pp. 848-856.

Warren, J. ed. 1999 Conservation of Earth Structures. London: Butterworth Heinemann. 